Karoliina Lummaa

\title{
Antroposeeni: ihmisen aika geologiassa ja kirjallisuudentutkimuksessa
}

\author{
[-- ] \\ It's the Apocalyptocene \\ It's the MadMaxocene \\ It's the ShitHits TheFanocene \\ It's the Y2KForRealThisTimeocene \\ It's the WeAllGetDarwinAwardsocene \\ It's the MoneyTalksNatureWalksocene \\ It's the VeryBadSceneocene \\ It's the Idiocene \\ Yes, folks. It's the Idiocene \\ Welcome to the Idiocene \\ $[--]$ \\ Se on apokalyptoseeni \\ Se on MadMaxseeni \\ Se on PaskaOsuuTuulettimeenseeni \\ Se on TälläKertaaOikeaY2Kseeni \\ Se on DarwinpalkintoMeilleKaikilleseeni \\ Se on RahaVoittaaLuontoHäviääseeni \\ Se on Tosipahaskeneseeni \\ Se on idioseeni \\ Kyllä, kaverit. Se on idioseeni \\ Tervetuloa idioseeniin
}

(Max Cafard, 2014. Suom. KL.) ${ }^{1}$

Yhdysvaltalaisen runoilijan Max Cafardin yhdeksän säkeistön pituinen ”Tervetuloa idioseeniin” on jo useamman vuoden ajan kiertänyt internetissä vihaisena ja turhautuneena kommenttina antroposeenikeskusteluihin, jotka ovat 2000-luvun aikana nopeasti levinneet geologiasta muihin luonnontieteisiin, yhteiskuntatieteisiin ja humanistisiin tieteisiin sekä taiteeseenkin. Antroposeeni on geologien puntaroima ehdotus uudeksi planeetan historiaa jäsentäväksi epookiksi holoseenin jälkeen. Se merkitsee planetaarisen ihmisvaikutuksen aikaa, joka jättää pysyvät jäljet Maapallon maa- ja kallioperään, kryosfääriin, ilmastoon, meriin, vesistöihin ja elonkehään sekä siten koko maapallojärjestelmän toimintaan. Yllä lainaamani Cafardin runon kymmenen viimeistä säettä - kuten runo kokonaisuudessaankin - korostaa anthropoksen eli ihmisen typeryyttä ja tuhoisuutta, mutta samalla runo reagoi antroposeenin käsitteen suosioon sekä vaihto- 
ehtoisten "-seenien" lukuisuuteen. Ihmistieteissä on nimittäin odotetusti reagoitu luonnontieteelliseen ajatukseen ihmisen ajasta ja keksitty koko joukko vaihtoehtoisia nimityksiä uudelle epookille.

Luon seuraavassa lyhyen katsauksen antroposeenikeskustelun nykytilaan. Nähdäkseni antroposeenissa on potentiaalia paitsi humanistisen ympäristötutkimuksen myös kirjallisuudentutkimuksen käsitteeksi.

\section{Antroposeeni luonnontieteissä}

Tämänhetkisen luonnontieteellisen antroposeenikeskustelun pohjana on Paul J. Crutzenin ja Eugene F. Stoermerin Global Change Newsletterissä toukokuussa 2000 julkaisema lyhyt artikkeli "The 'Anthropocene'”. Siinä Crutzen ja Stoermer ehdottavat, että viimeisin, noin 100000 tuhatta vuotta sitten alkanut holoseenin epookki on päättynyt, ja olemme siirtyneet antroposeeniin. Antroposeeni on siis luonnontieteissä ennen kaikkea Maapallon ajanlaskua määrittävä käsite. Maapallon kerrostumia mittaavassa stratigrafiassa Maapallon ikää jäsentävät aionit (engl. Eon, puolesta miljardista kahteen miljardia vuotta), maailmankaudet (engl. Era, satoja miljoonia vuosia), kaudet (engl. Period, yleensä alle sata miljoonaa vuotta), epookit (engl. Epoch, kymmeniä miljoonia vuosia) sekä vaiheet (engl. Age, esim. Jäkausi). Ihmisen historian kannalta merkittävin on 23 miljoonaa vuotta sitten alkanut neogeenikausi, joka jakautuu mioseeniin ja plioseeniin sekä kvartäärikausi, joka jakautuu pleistoseeniin, holoseeniin ja antroposeeniin. Neogeenikaudella kehittyvät ensimmäiset ihmistä muistuttavat apinat sekä suuri joukko nykyisiä lajeja muistuttavia nisäkäs- ja lintuheimoja. Kvartäärikauden ensimmäisen epookin, noin 2,5 miljoonaa vuotta sitten alkaneen pleistoseenin aikana kehittyy nykyihminen. Jääkauden viimeisimmän jäätiköitymisvaiheen lopussa alkaa leudon ilmaston aika, holoseeni, jonka aikana ihmisen kulttuuri pääsee toden teolla kehittymään muuntuakseen lopulta geologiseksi voimaksi, jolloin on siirrytty antroposeeniin.

Milloin antroposeeni sitten tarkalleen ottaen alkoi? Edellä viittaamani Crutzen ja Stoermer ehdottavat alkamisajankohdaksi 1700-luvun jälkipuoliskoa eli teollistumisen ajan alkua, koska tässä vaiheessa Maapallon ilmasto on jänäytteiden perusteella alkanut muuttua radikaalisti: etenkin hiilidioksidin ja metaanin määrä ilmakehän kaasukoostumuksessa kasvaa. Viimeisen kahden vuosisadan ajalta Crutzen ja Stoermer mainitsevat laajan joukon muitakin antropogeenisiä eli ihmislähtöisiä ympäristömuutoksia, kuten väestönkasvun ja karjan määrän kasvun, maankäytön muutokset sekä rikkidioksidi- ja typpimonoksidipäästöt, jotka kaikki vaikuttavat radikaalisti Maapalloon ja sen elonkehään. (Cruetzen \& Stoermer 2000, 17-18.) Antroposeenin alkuajankohdaksi on ehdotettu varhaisempaakin aikaa, 1600-luvun alkua. Simon Lewis ja Mark Maslin (2015) ajoittavat antroposeenin nimittäin vaiheeseen, jossa Amerikan alkuperäisväestö tuhoutuu eurooppalaisten saapumiseen ja Pohjois-Amerikan manner alkaa metsittyä 
uudelleen. Tiedeyhteisössä tämä ehdotus ei ole saanut kannatusta, koska vastaavia murroksia on tapahtunut muinakin aikoina.

Todennäköisesti antroposeenin alku tullaan sijoittamaan vuoteen 1950, jolloin 1940-luvun jälkipuoliskolla alkaneiden ydinkokeiden vaikutukset näkyvät maaperässä. Tällä ehdotuksella on institutionaalinen taustansa: Kansainvälinen stratigrafian komissio (International Commission on Stratigraphy, ICS) perusti vuonna 2009 virallisen Antroposeeni-työryhmän (Anthropocene Working Group, AWG), jonka tarkoitus on käsitellä antroposeenin hyväksymistä geologiseksi ajanjaksoksi. Loppuvuodesta 2016 työryhmä ehdotti, että antroposeeni sijoitettaisiin stratigrafiseen kerrosjärjestykseen holoseenin seuraajaksi vuodesta 1950 alkaen. Viralliseen kerrosjärjestykseen antroposeeni voidaan hyväksyä vasta, kun sille on märitelty stratigrafiset tunnusmerkit ja se on saanut enemmistön kannatuksen Kansainvälisen stratigrafian komissiossa. Tämän odotetaan tapahtuvan lähivuosina.

Luonnontieteiden sisällä käyty antroposeenikeskustelu ilmentää geologisten ja biologisten ilmiöiden tutkimusmenetelmien ja -perinteiden välillä tapahtuvia muutoksia ja jännitteitä. Geologian alaan kuuluva stratigrafia tutkii Maapallon kerrosjärjestystä, ennen kaikkea toisiinsa yhteydessä olevien makerrosten ja rakenteiden muodostamia sarjoja sekä sitä, miten ne suhteutuvat toisiinsa. Stratigrafian kannalta antroposeenin on oltava havaittavissa Maan kerroksissa. Planetaarisia prosesseja kuten ilmakehää, vesikehää ja elonkehää sekä niiden systeemisiä keskinäisvaikutuksia tutkiva maapallojärjestelmätiede (Earth System Science, ESS) puolestaan ymmärtää antroposeenin laajemmin useiden erilaisten ihmisvaikutuksesta syntyneiden ilmiöiden joukkona. Maapallojärjestelmätieteen näkökulmasta antroposeeni tarkoittaa erilaisia systeemisiä muutoksia, joiden tutkimiseen tarvitaan paitsi luonnontieteellistä myös yhteiskuntatieteellistä ymmärrystä ja menetelmiä. Geologiassa ja maapallojärjestelmätieteessä esitetyt arviot antroposeenin nimeämisen tarpeellisuudesta vaihtelevat suuresti: pitkiä ajanjaksoja taaksepäin katsovan geologian piirissä antroposeenia on pidetty ongelmallisena tai jopa tarpeettomana (esim. Finney \& Edwards 2016), kun taas maapallojärjestelmätieteessä antroposeenin käsite kohdistaa erilaisten systeemisten muutosten alkuperän ihmisen toimintaan heuristisella tavalla. ${ }^{2}$

\section{Kiinnostusta ja kiistelyä ihmistieteissä}

Kun luonnontieteilijät nostavat tutkimuskohteekseen ihmisen vaikutuksen, herää yhteiskuntatieteilijöiden ja humanistien kiinnostus väistämättä. Erityisesti yhteiskuntatieteilijät ovat tarttuneet ihmisen planetaarisen vaikutuksen ajatukseen hanakasti ja kysyneet, kuka tämä ihminen tarkalleen ottaen on. Laajimmat ja vakavimmat antropogeeniset ympäristömuutokset ja -ongelmat ovat valtaosin vauraiden länsimaiden tuottamia (Chakrabarty 2009; Moore 2015). Ongelmallinen on myös universalisoiva ajatus ihmi- 
sestä tai ihmisyydestä jonakin, joka voidaan asettaa antroposeenin arkkitehdiksi pohtimatta vaikkapa talousjärjestelmien tai muiden valtarakenteiden vaikutuksia toteutuneeseen kehitykseen (Malm \& Hornborg 2014; Hartley 2016). Antroposeenin rinnalle onkin noussut useita vaihtoehtoisia nimityksiä, kuten kapitaloseeni (Capitalocene), Chthuluseeni (Chthulucene), sosioseeni (Sociocene), ekonoseeni (Econocene), antroboseeni (Anthrobocene) tai teknoseeni (Technocene), jotka korostavat erilaisin painotuksin länsimaisen kulttuurin teknisiä, teollisia, kaupallisia ja konsumeristisia puolia.

Humanististen tieteiden parissa antroposeenista ovat kirjoittaneet ennen kaikkea taiteentutkijat ja filosofit, jotka lähestyvät taidetta ja kulttuuria ympäristöllisistä tai aineellisista lähtökohdista. Antroposeenin käsite on toisin sanoen vakiintunut toistaiseksi lähinnä ekokriittiseen, posthumanistiseen ja uusmaterialistiseen tutkimukseen sekä filosofiaan, jossa luonnonresursseja, energiaa, ilmastoa ja jätteitä tarkastellaan kulttuurisina kysymyksinä. Esiin on nostettu ensinnäkin antroposeenin käsitteen ristiriitaisuus suhteessa posthumanistiseen ajatteluun. Teoksessaan Hyperobjects. Philosophy and Ecology after the End of the World (2013) kirjallisuudentutkija ja ympäristöfilosofi Timothy Morton kritisoi antroposeenin käsitettä siitä, että se nostaa ihmiset uuden epookin keskiöön. Mortonin mukaan nyt eletään päinvastoin aikaa, jona ihmiset tulevat tietoisiksi erilaisten ei-inhimillisten olioiden ja prosessien vaikuttavuudesta (Morton 2013, 5-9). Yleisin Mortonin esimerkki tällaisista ei-inhimillisistä toimijoista on lämpenevä ilmasto ja siihen liittyvät rajut sääilmiöt, mutta hän kirjoittaa myös atomipommeista ja radioaktiivisesta jätteestä sekä hitaasti hajoavista muoveista ja öljystä, jotka kaikki vaikuttavat sekä ympäristöömme (ja elimistöihimme) että ajatteluumme.

Myös tieteentutkija ja filosofi Bruno Latour pitää antroposeenia paradoksaalisena ilmiönä. Eräässä taiteen, tieteen ja politiikan kytköksiä käsittelevässä luennossaan hän nostaa esiin, että käsitykset antroposeenista ja post-inhimillisestä eli ihmisenjälkeisestä ovat ristiriitaisesti läsnä tämänhetkisessä kriittisessä teoriassa ja keskustelussa:

Antroposeeni-argumentissa ironista on se, että se ilmaantuu aikana jolloin eturivin filosofit puhuvat ajastamme "post-inhimillisenä" aikana; ja juuri samaa aikaa toiset ajattelijat ovat ehdottaneet "historian lopuksi". Näyttää siltä, että sekä historialla että luonnolla on enemmän kuin yksi temppu hihassaan, sillä näemme nyt historian nopeuden kiihtyvän ja sen mittaluokan muuttuvan käänteessä, jota ei ehkä pitäisi kutsua post-inhimilliseksi vaan post-luonnolliseksi! Jos "anthropos" todella muuttaa Maapalloa kirjaimellisesti (eikä vain metaforisesti, symbolein), olemme todistamassa antropomorfismia steroideissa. (Latour 2011, 3. Suom. KL.) ${ }^{3}$

Samaan tapaan antroposeenin ja posthumanismin ristiriitaisuudesta kirjoittaa ekokriitikko Ursula K. Heise teoksessaan Imagining Extinction. The Cultural Meanings of Endangered Species (2016). Antroposeenin idea on hänen mukaansa jännitteisessä suhteessa sellaisiin posthumanistisiin näkemyksiin, jotka korostavat ei-inhimillisten toimi- 
joiden merkitystä ihmisten toiminnassa ja suhteissa (Heise 2016, 203). Antroposeeni ja posthumanismi todella ovat käsitteellisesti toisissaan kiinni: antroposeeni käsittelee ihmisen aikaa ja vaikutuksia - posthumanismi käsittelee ihmisyyden reunoja ja niiden ylityksiä. Molemmissa on kysymys ihmisen yli- ja alivoimasta sekä kaikenlaisista jännitteistä suhteessa maailmaan ja olioihin.

Keskustelu antroposeeni-epookin ja post-inhimillisen ajan ristiriitaisuuksista liittyy tietysti laajempaan kysymykseen ihmiskäsitysten murroksista. Sekä antroposeeni että posthumanismi syntyvät tieteellisinä käsitteellistyksinä tilanteeseen, jota hallitsevat hyvin ristiriitaiset kuvat ihmisen mahdollisuuksista ja tulevaisuuksista. Onkin syytä korostaa, että antroposeeni esiintyy ihmistieteissä ja taiteessa geologisen epookin rinnalla käsitteenä. Antroposeeni on käsitteellinen väline ihmisen ja ihmisyyden ymmärtämiseen geologisesta ja biologisesta näkökulmasta eli planeettaa ja sen elonkehää muokkaavana voimana (Szerszynski 2012; Palsson et al. 2013; Holm et al. 2015; Cohen \& Colebrook 2016). Käsite on tarpeeksi avoin filosofiselle pohdinnalle ja taiteellisille tulkinnoille, mutta samalla sillä on tarpeeksi laaja perusta luonnontieteellisissä ja yhteiskuntatieteellisissä keskusteluissa (vaikkakaan antroposeenin ajoituksesta ja todentamisesta ei ole vielä yksimielisyyttä).

Taiteentutkijat ovat kiinnittäneet huomiota antroposeenin aistimellisuuteen ja kokemuksellisuuteen. Heather Davis ja Etienne Turpin kirjoittavat antroposeenista muuntuneiden ympäristökokemusten aikana, jolloin aistimme uudenlaista, myrkyttyvää ja lajikirjoltaan yksipuolistuvaa luontoa. Aistiminen liittyy Davisin ja Turpinin mukaan myös antroposeenin todentamiseen, joka ei tapahdu luonnossa sinänsä vaan erilaisten havainnekuvien, kaavioiden ja taulukoiden avulla. Antroposeenin epookkiin siirtymistä konkretisoivat toisin sanoen erilaiset visuaaliset todisteet. Antroposeenin aistimellisuutta luonnehtii myös se, että kokemukset tästä epookista sekä merkitykset, joita sille ja siitä syntyville kokemuksille annetaan, tapahtuvat taiteen välityksellä. (Davis \& Turpin 2015.) Antroposeenin kokemuksellisuudesta on kirjoittanut myös jo esillä ollut Morton, joka korostaa todellisuuden epäselvyyttä ja häilyvyyttä. Antroposeenissa erilaiset ei-inhimilliset oliot ja ilmiöt, kuten aiemmin mainitut atomipommit ja öljyvuodot mutta myös biosfääri tai evoluutio, näyttäytyvät aktiivisina toimijoina, jotka nakertavat selkeää erottelua luonnon ja kulttuurin välillä, muokkaavat ja mullistavat asioita ja prosesseja, joita ihminen yrittää hallita, sekä ilmentävät ajallisia ja paikallisia mittakaavoja jotka haastavat inhimillisen käsityskyvyn. Toisin kuin romanttisesti tai postmodernistisesti tulkittu ymmärryskyvyn haastava ylevä nämä mittakaavan ylityksiä tuottavat hyperobjektit uhkaavat tai muuntavat ihmisiä ja ei-ihmisiä myös konkreettisesti, fyysisellä tasolla. (Morton 2013.)

Antroposeeni siis puhuttaa taiteentutkijoita, mutta humanistiset tieteet ovat toki omaksuneet luonnontieteistä käsitteitä ennenkin. Ympäristökysymysten ja luonto- 
esitysten käsittelyssä erityisesti ekologian ja ympäristötieteen käsitteet ovat olleet käytettyjä, vähintäänkin merkityksellisten aiheiden (biodiversiteetti, ekologinen lokero) tai ongelmien (otsonikato, ilmastonmuutos) nimeämisessä. Joskus käyttökelpoiset käsitteet jäävät soveltamatta: näin on käynyt esimerkiksi ekosysteemipalveluille, jollaisina kaunokirjallisuuttakin voitaisiin lähestyä. Antroposeenin suosio liittynee paitsi edellä mainittuihin ihmisvaikutuksen eksplisiittiseen nimeämiseen ja käsitteen avoimuuteen myös siihen, että se ilmentää eri tieteenalojen erityispiirteitä. Geologin, luonnonsuojelubiologin, antropologin tai poliittisen historian tutkijan antroposeenit ovat keskenään hyvin erilaisia. Millainen on kirjallisuudentutkijan antroposeeni?

\section{Kirjallisuudentutkimus ja antroposeeni}

Kirjallisuudentutkimuksen alalla antroposeenista ovat keskustelleet ennen kaikkea ekokriitikot. Teoksessaan Imagining Extinction. The Cultural Meanings of Endangered Species (2016) saksalainen ekokriitikko Ursula K. Heise tutkii sukupuuton esityksiä tieteellisissä ja kaunokirjallisissa teksteissä sekä populaarikulttuurissa, ja hän omistaa antroposeenin kysymyksille kokonaisen luvun. Heise (2016, 203-206) jakaa antroposeenin optimistiseen ja pessimistiseen tulkintaan, joista ensin mainittu keskittyy ihmisen mahdollisuuksiin kuvitella ja suunnitella luonto "uudelleen" ja toiseksi mainittu ympäristöjen ja lajien vääjäämättömään tuhoutumiseen. Pessimistinen antroposeeni on oikeastaan apokalyptisten ympäristönarratiivien huipentuma, koska ihmisen katastrofaalinen jälki porautuu maa- ja kallioperään asti, geologiseksi jäljeksi (Heise 2016, 206). Koska pessimistisen antroposeenin esimerkkejä on helppo keksiä, lainaan mieluummin Heisen esimerkin optimistisesta antroposeenista. Heise $(2016,206)$ on ottanut seuraavan suoran sitaatin Diane Ackermanin teoksesta The Human Age: The World Shaped by Us (2014):

Näinä päivinä [- - ] me hallitsemme omaa perintöämme. Emme ole passiivisia, emme avuttomia. Olemme maailman muuttajia. Meistä voi tulla Maan ennallistajia ja Maan suojelijoita. Meillä on vielä aikaa ja mielikuvitusta, ja lukuisia vaihtoehtoja. Virheemme ovat lukuisat, mutta lahjakkuutemme on mittaamaton. (Suom. KL) ${ }^{4}$

Heise arvostaa antroposeenia optimistisesti lähestyviä näkökulmia, koska hän epäilee ympäristöliikkeeseen liittyvää nostalgista suhtautumista menetettyyn luontoon ja elegistä suhtautumista katoaviin lajeihin. Hän tuo esiin myös syväekologisten ympäristöliikkeiden piilevän ihmisvihan. Toisaalta hän kysyy, mitkä ovat ihmisen mahdollisuudet lopulta vaikuttaa ympäristöön, jossa vaikuttavat myös geologiset ja ulkoplanetaariset voimat. Kaiken kaikkiaan Heise pelkää, että ihmisen on lopulta alettava hallita Maata; hän kutsuu esiin ihmisten ekologista toimijuutta (ecoagency). (Heise 2016, 209.)

Heise lähestyy antroposeenia ihmisen planetaarista paikkaa ja voimaa jäsentävänä käsitteenä, ja hänen kannanottonsa ankkuroituvat monin tavoin yhteiskuntatieteelliseen 
kritiikkiin antroposeenin universalisoivasta ihmiskäsityksestä (Heise 2016, 220-223). Kaunokirjallisuudessa hän nostaa antroposeenitulkinnoista esiin ennen kaikkea tieteisfiktiossa esitetyt optimistiset näkymät, joissa ekosysteemejä kyetään ennallistamaan ja sukupuuttoon kuolleita lajeja palautetaan elämään joko Maapallolle tai muille ihmisten asuttamille planeetoille. (Heise 2016, 209-215.) Sukupuuton peruutus (de-extinction) ja uudelleen-villiyttäminen (re-wilding) liittyvät laajempaan maan muokkaamisen (terraforming) tematiikkaan, jossa ihminen ottaa haltuunsa globaalit ekosysteemit (Heise 2016, 212). Heisen mukaan tällaiset kuvaukset ilmentävät antroposeenin luonnon toisenlaista luonnollisuutta, jota on taiteen ja taiteentutkimuksen parissa luonnehdittu myös seuraavaksi luonnoksi (next nature), post-luonnolliseksi (post-natural), tulevaisuusluonnolliseksi (futurenatural) tai enemmän-kuin-luonnoksi (preternatural) (Heise 2016, 215; Latour 2011; Robertson et al. 1996; Jeffery 2011). Suomen kielessä voisi puhua vaikkapa tois-luonnosta ja tois-luonnollisuudesta.

Muun muassa Kim Stanley Robinsonin, William Gibsonin, Octavia Butlerin, Sheri S. Tepperin ja Margaret Atwoodin teoksia analysoidessaan Ursula Heise nostaa esiin tematiikan, joka on kirjallisuudentutkimuksellisen antroposeenikeskustelun kannalta olennainen: antroposeeni toimii spekulatiivisen fiktion trooppina. Heise viittaa Fredric Jamesonin teokseen Archaeologies of the Future: The Desire Called Utopia and Other Science Fictions (2005), jossa Jameson esittää, että tieteisfiktion tarkoitus on näyttää lukijoilleen nykyisyys uudella tavalla, tulevien yhteiskuntien menneisyytenä. Nykyinen spekulatiivinen fiktio käsittelee nykyisyyttä kahdella tavalla: nykyhetki esitetään toisaalta kuviteltujen tulevaisuuksien menneisyytenä, ja toisaalta nykyhetkeä katsotaan miltei käsillä olevasta tulevaisuudesta käsin siten, että nykyhetki näyttäytyy vanhentuneena. Heisen mielestä antroposeeni kytkeytyy ennen kaikkea jälkimmäiseen eli siihen, että tulevaisuus tavallaan on jo tapahtunut meille: "se [antroposeeni] keskittyy muunnellun planeetan todellisuuteen, joka on [tieteisfiktion] genressä pitkään ajateltu muiden planeettojen tulevaisuuden visioksi, mutta joka on jo saapunut oman planeettamme nykyhetkeen"5 (Heise 2016, 219-220, suom. KL).

Heise kiinnittää antroposeenia koskevat näkemyksensä tieteisfiktioon ja sen tutkimukseen, mutta hänen ajatuksensa antroposeenin tulevaisuusorientoituneesta ja spekulatiivisesta käsittelystä koskee mielestäni kirjallisuutta, taidetta ja näiden tutkimusta yleisemminkin. Toisin kuin menneisyyden kerrostumia tutkiva ja luokitteleva stratigrafia, taiteentutkimus katsoo antroposeenia spekulatiivisesta tulevaisuuden näkökulmasta. Esimerkiksi Claire Colebrook $(2014,24)$ tulkitsee antroposeenin käsitettä juuri näin esittäessään, että ihmisen epookki tai aika sisältää ajatuksen maailmasta ihmisen jälkeen. Ihmisen vaikutus tulee olemaan todennettavissa sellaisessa tulevaisuudessa, jossa nykyinen ihminen, Homo sapiens kuuluu menneisyyteen. Myös Heather Davis ja Etienne Turpin $(2015,9)$ ajattelevat pitkälle tulevaisuuteen kritisoidessaan 
yhteiskuntatieteilijöiden esittämiä euroseenin (Eurocene), teknoseenin, kapitaloseenin ja plantationoseenin (Plantationocene) käsitteitä, jotka kyllä selittävät planeetan tämänhetkisen tilan sosiaalisia ja materiaalisia taustoja muutaman sadan vuoden ajalta, mutta jotka tuskin kuvaavat seuraavaa 10000 vuotta. Antroposeenissa keskeistä on ajallisuus. Etienne Turpin $(2013,10)$ kutsuukin antroposeenia eräässä yhteydessä kronotoopiksi, mutta ei kehittele ajatusta pidemmälle.

Mainitsin edellä antroposeenin käsitteellisistä mahdollisuuksista eri tieteenalojen itsereflektion välineenä. Antroposeenikeskusteluissa taiteesta ja kaunokirjallisuudesta sekä niiden tutkimuksesta nousee aina esille näiden alojen työskentely fiktioiden parissa sekä siten niiden spekulatiivinen luonne. Taiteen- ja kirjallisuudentutkimus kokoaa ja tulkitsee taiteessa esitettyä ja ilmaistua; se on spekulatiivista mahdollisten tapahtumien, olioiden, ideoiden ja esitysmuotojen tarkastelua. Kriittisen analyysin rinnalla kirjallisuudentutkimus voi kokeilla käsitteillä ja ideoilla sekä siten rakentaa vaihtoehtoisia ajattelemisen ja toiminnan tapoja. Sillä on siis paljonkin annettavaa ihmisen ja ympäristön tai ihmisten ja muiden olioiden suhteiden tutkimiselle, mutta nimenomaan tässä spekulatiivisessa tai fiktioita luotaavassa ja niitä ymmärtävässä ja tulkitsevassa mielessä. Kirjallisuudentutkijoiden tapa lähestyä antroposeenia fiktioiden ja spekulaatioiden kautta voi siten olla hyvinkin erilainen kuin yhteiskuntatieteilijöiden, jotka keskittyvät tosiasiallisiin historiallisiin sosiaalisiin prosesseihin - prosesseihin, jotka toki ovat monin tavoin läsnä kirjallisuudentutkimuksessakin, tutkimuksenteon ja tulkintojen moninaisina konteksteina.

Antroposeenin käsitettä ja siitä käytyä keskustelua voi lukea tiede- ja taidemaailman yrityksenä ottaa haltuun globaalit ympäristö- ja resurssikriisit ekologisine, sosiaalisine ja kulttuurisine kytköksineen ja tulkintoineen. Näiden ongelmien ja niihin liittyvien ilmiöiden keskiössä on ihminen - miten ihmisen haluammekaan ymmärtää. Meidän ei kirjallisuudentutkijoina siis tarvitse kiinnittyä työssämme suoraan ympäristö- ja resurssikriiseihin ollaksemme kiinnostuneita antroposeenista. Onhan työmme kannalta joka tapauksessa oleellista nähdä, miten ihmisen paikka, asema ja voima tällä hetkellä käsitetään, ja millaisia ajattelun, tieteen ja kulttuurin murroksia tällä hetkellä on syntymässä.

\section{Viitteet}

${ }^{1}$ Luettavissa esim. osoitteessa https://theanarchistlibrary.org/library/max-cafard-welcome-tothe-idiocene

${ }^{2}$ Luonnontieteellisistä ja yhteiskuntatieteellisistä antroposeenikeskusteluista kiinnostuneita lukijoita kehotan lukemaan artikkelin "Kenen antroposeeni? Maapallojärjestelmätieteen paradigmamuutos, ihmistieteiden antroposeeni ja käsitteiden moninaisuus" (Eronen et al. 2016). Tässä katsauksessa esitetyt luonnontieteelliset ja yhteiskuntatieteelliset näkemykset pohjaavat mainittuun artikkeliin. Kiitän Jussi T. Erosta kaikista huomioista ja korjauksista, jotka koskevat luonnontieteellistä osuutta tässä katsauksessa. Kiitän myös Tero Toivasta yhteiskuntatieteellisen antroposeenikeskustelun yksityiskohtien avaamisesta. 
3 "What is so ironic with this Anthropocene argument is that it comes just when vanguard philosophers were speaking of our time as that of the 'posthuman'; and just at the time when other thinkers were proposing to call this same moment the 'end of history'. It seems that history as well as nature have more than one trick in their bag, since we are now witnessing the speeding up and scaling up of history not with a posthuman but rather with what should be called a post-natural twist! If it is true that the 'anthropos' is able to shape the Earth literally (and not only metaphorically through its symbols), what we are now witnessing is anthropomorphism on steroids." (Latour 2011,3.)

4 "These days...we control our own legacy. We're not passive, we're not helpless. We're earth-movers. We can become Earth-restorers and Earth-guardians. We still have time and imagination, and we have a great many choices...Our mistakes are legion, but our talent is immeasurable." (Heise 2016, 206; sit. Ackerman 2014.)

5 "[I]t [the Anthropocene] focuses on the reality of a terraformed planet that the genre has long held out as a vision for the future of other planets, but which has already arrived in the present on our own planet" (Heise 2016, 219-220).

\section{Kirjallisuus}

Chakrabarty, Dipesh 2009. The climate of history: Four theses. Critical Inquiry 35(2), 197-222.

Cohen, Tom \& Claire Colebrook 2016. Preface. Tom Cohen, Claire Colebrook \& J. Hillis Miller (eds), Twilight of the Anthropocene Idols. Ann Arbor, Michigan: Open Humanities Press, 7-19.

Colebrook, Claire 2014. Death of the Posthuman. Essays on Extinction, Vol. 1. Ann Arbor, Michigan: Open Humanities Press.

Crutzen, Paul J. \& Eugene F. Stoermer 2000. The 'Anthropocene'. IGBP Newsletter $41,17-18$.

Davis, Heather \& Etienne Turpin 2015. Art \& Death: Lives Between the Fifth Assessment \& the Sixth Extinction. Heather Davis \& Etienne Turpin (eds), Art in the Anthropocene. Encounters Among Aesthetics, Politics, Environments and Epistemologies. Ann Arbor, Michigan: Open Humanities Press, 3-29.

Eronen, Jussi, Karoliina Lummaa, Tero Toivanen, Ville Lähde, Paavo Järvensivu, Antti Majava \& Tere Vadén 2016. Kenen antroposeeni? Maapallojärjestelmätieteen paradigmamuutos, ihmistieteiden antroposeeni ja käsitteiden moninaisuus. Kosmopolis 46(4), 41-54.

Finney, Stanley C. \& Lucy E. Edwards 2016. The ”Anthropocene” Epoch : Scientific Decision or Political Statement? GSA Today 26(3), 4-10.

Haraway, Donna 2016. Staying with the Trouble: Making Kin in the Chthulucene. Duke University Press. 
Hartley, Daniel 2016. Anthropocene, Capitalocene, and the Problem of Culture. Jason W. Moore (ed.), Anthropocene or Capitalocene? Nature, History, and the Crisis of Capitalism. Oakland: PM Press, 154-165.

Heise, Ursula K. 2016. Imagining Extinction. The Cultural Meanings of Endangered Species. Chicago \& London: The University of Chicago Press.

Holm, Poul, Joni Adamson, Hsinya Huang, Lars Kirdan, Sally Kitch, Iain McCalman, James Ogude, Marisa Ronan, Dominic Scott, Kirill Ole Thompson, Charles Travis \& Kirsten Wehner 2015. Humanities for the Environment - A Manifesto for Research and Action. Humanities 4(4), 977-992.

Jeffery, Celina (ed.) 2011. Preternatural. New York: Punctum Books.

Latour, Bruno 2011. Waiting for Gaia. Composing the Common World through Arts and Politics. A lecture at the French Institute, London, November 2011 for the launching of SPEAP (the Sciences Po Program in Arts \& Politics). http://www. bruno-latour.fr/node/446 (19.3.2017).

Lewis, Simon L. \& Mark A. Maslin 2015. Defining the Anthropocene. Nature 519, 171-180.

Malm, Andreas \& Alf Hornborg 2014. The Geology of Mankind? A Critique of the Anthropocene Narrative. The Anthropocene Review 1(1), 62-69.

Moore, Jason W. 2015. Capitalism in the Web of Life: Ecology and the Accumulation of Capital. New York: Verso Books.

Morton, Timothy 2013. Hyperobjects. Philosophy and Ecology after the End of the World. Minneapolis \& London: University of Minnesota Press.

Palsson, Gisli, Bronislaw Szerszynski, Sverker Sörlin, John Marks, Bernard Avril, Carole Crumley, Heide Hackmann, Poul Holm, John Ingram, Alan Kirman, Mercedes Pardo Buendía \& Rifka Weehuizen 2012. Reconceptualizing the 'Anthropos' in the Anthropocene: Integrating the social sciences and humanities in global environmental change research. Environmental Science \& Policy 28 (2013) 3-13.

Robertson, George, Melinda Mash, Lisa Tickner, Jon Bird, Barry Curtis \& Tim Putnam (eds) 1996. FutureNatural. Nature, Science, Culture. London \& New York: Routledge.

Szerszynski, Bronislaw 2012. The End of the End of Nature. The Anthropocene and the Fate of the Human. Oxford Literary Review 34(2), 165-184.

Turpin, Etienne 2013. Introduction: Who Does the Earth Think It Is, Now? Etienne Turpin (ed.), Architecture in the Anthropocene. Encounters Among Design, Deep Time, Science and Philosophy. Ann Arbor, Michigan: Open Humanities Press, 3-10. 